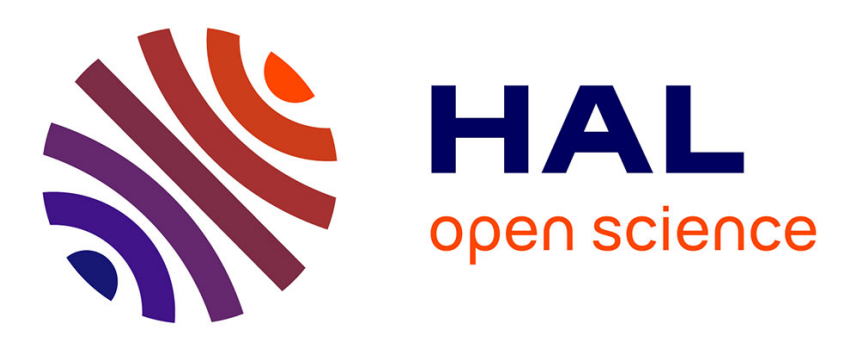

\title{
Intrinsic and light induced gap states in a-Si:H materials and solar cells-effects of microstructure
}

C. R. Wronski, J.M. Pearce, J. Deng, V. Vlahos, R. W. Collins

\section{To cite this version:}

C. R. Wronski, J.M. Pearce, J. Deng, V. Vlahos, R. W. Collins. Intrinsic and light induced gap states in a-Si:H materials and solar cells-effects of microstructure. Thin Solid Films, 2004, 451-452, pp.470-475. 10.1016/j.tsf.2003.10.129 . hal-02120528

\section{HAL Id: hal-02120528 \\ https://hal.science/hal-02120528}

Submitted on 6 May 2019

HAL is a multi-disciplinary open access archive for the deposit and dissemination of scientific research documents, whether they are published or not. The documents may come from teaching and research institutions in France or abroad, or from public or private research centers.
L'archive ouverte pluridisciplinaire HAL, est destinée au dépôt et à la diffusion de documents scientifiques de niveau recherche, publiés ou non, émanant des établissements d'enseignement et de recherche français ou étrangers, des laboratoires publics ou privés. 


\title{
INTRINSIC AND LIGHT INDUCED GAP STATES IN A-SI:H MATERIALS AND SOLAR CELLS - EFFECTS OF MICROSTRUCTURE
}

\author{
C. R. Wronski, J. M. Pearce, J. Deng, V. Vlahos, R.W. Collins \\ Center for Thin Film Devices, Penn State University, University Park, PA, 16802, USA
}

\begin{abstract}
The effects of microstructure on the gap states of hydrogen diluted and undiluted hydrogenated amorphous silicon (a-Si:H) thin film materials and their solar cells have been investigated. In characterizing the films the commonly used methodology of relating just the magnitudes of photocurrents and subgap absorption, $\alpha(E)$, was expanded to take into account states other than those due to dangling bond defects. The electron mobility-lifetime products were characterized as a function of carrier generation rates and analysis was carried out of the entire $\alpha(E)$ spectra and their evolution with light induced degradation. Two distinctly different defect states at 1.0 and $1.2 \mathrm{eV}$ from the conduction band and their contributions to carrier recombination were identified and their respective evolution under 1 sun illumination characterized. Direct correlations were obtained between the recombination in thin films with that of corresponding solar cells. The effects of the difference in microstructure on the changes in these two gap states in films and solar cells were also identified It is found that improved stability of protocrystalline $\mathrm{Si}: \mathrm{H}$ can in part be attributed to the reduction of the $1.2 \mathrm{eV}$ defects. It is also shown that ignoring the presence of multiple defects leads to erroneous conclusions being drawn about the stability of a-Si:H and SWE.
\end{abstract}

Keywords: amorphous silicon, microstructure, gap states, light induced defects, solar cells PACS codes: 61.43.D, 68.55.L, 71.55J, 84.60.J

\section{Introduction}

It has been well established that microstructural changes in hydrogenated amorphous silicon (a-Si:H) materials resulting from differences in deposition conditions play an important role in the performance, and in particular the stability of their solar cells. There is currently a large interest in this for a-Si:H deposited at high rates as well as novel materials having different microstructure such as in protocrystalline $\mathrm{Si}: \mathrm{H}$, often called "edge" a-Si:H [1,2]. It is still not clear what the effects of microstructure are on the gap states of these as well as other materials.

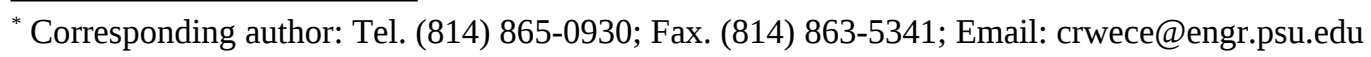


Pre-print E-MRS Spring 2003 June $10^{\text {th }}-13^{\text {th }}$ Strasbourg, France, Published: Wronski, C. R., J. M. Pearce, J. Deng, V. Vlahos, and R. W. Collins. "Intrinsic and light induced gap states in a-Si: H materials and solar cells_effects of microstructure." Thin Solid Films 451 (2004): 470-475. http://dx.doi.org/10.1016/j.tsf.2003.10.129

There is also a lack of direct, quantitative correlations between the results obtained for the defect states in thin films with those in the corresponding intrinsic layers in solar cells, particularly those with the highest performance. Part of the absence of direct correlations, even in simple cell structures, can be due to possible differences in the thin film materials and those in the intrinsic layers of the cells as well as inadequate characterization of the defect states in the films with the commonly methods used in characterizing them. Various reasons for differences in the intrinsic materials have been proposed such as dopants diffusing from the n- and p-layers and nonuniform distribution of gap states across the i-region predicted by the defect pool model [3]. In the work described here the effect of such possibilities was taken into account by investigating different cell structures. Also account was taken of the evolution in the microstructure of hydrogen diluted materials and its dependence on substrate [4] in order to ensure that only the amorphous phase was present in both the cell i-layers and the $\sim 1 \mu \mathrm{m}$ thick films. When characterizing the thin films, the commonly used methodology of measuring just the photocurrents was extended to that of the electron mobility-lifetime products $(\mu \tau)$ as a function of carrier generation rates (G). In addition, an approach was developed in the analysis of subgap absorption, $\alpha(E)$, which addresses the presence of non- $\mathrm{D}^{\mathrm{O}}$ (neutral dangling bond) defect states.

Here we report on studies in which direct correlations have been established between the recombination in thin films and solar cells, as well as the effects of changes in microstructure on the defect states in the materials. These studies were carried out on protocrystalline Si:H materials prepared with hydrogen dilution as well as those deposited at different rates without hydrogen dilution. Results are presented which identify two distinctly different defect states in a$\mathrm{Si}: \mathrm{H}$ around and below midgap and characterize their effects on carrier recombination. Results are also presented on the light induced changes in these two gap states that illustrate the effects of microstructure on their creation and annealing kinetics in both films and solar cells.

\section{Discussion}

\subsection{Protocrystalline Si:H}

Using real time spectroscopic ellipsometry, deposition phase diagrams have been developed that describe how the microstructure and the phase evolve during the growth of Si:H films on different substrates [4]. Specifically, such diagrams identify the different phase regimes of accumulated bulk layer thickness within which a-Si:H grows, as well as the thicknesses at which subsequent transitions to mixed-phase, amorphous + microcrystalline Si:H $[(\mathrm{a}+\mu \mathrm{c})-\mathrm{Si}: \mathrm{H}]$ and then to single-phase microcrystalline $\mathrm{Si}: \mathrm{H}(\mu \mathrm{c}-\mathrm{Si}: \mathrm{H})$ occur, all as a function of a key deposition parameter. The hydrogen dilution flow ratio, $\mathrm{R}=\left[\mathrm{H}_{2}\right] /\left[\mathrm{SiH}_{4}\right]$, is used because it provides the most direct control over the phase. A schematic of the structure of Si:H films derived from phase diagrams prepared as a function of $\mathrm{R}$ is shown in Fig. 1 for Si:H deposited onto an $\mathrm{R}=0$ substrate layer under the conditions previously described [4]. Deposition phase diagrams have led to the concept of the protocrystalline Si:H growth regime indicated in the figure.

In addition to the unique evolutionary growth behavior exhibited under protocrystalline $\mathrm{Si}: \mathrm{H}$ growth conditions, the protocrystalline material itself exhibits unique opto-electronic properties. Perhaps the key feature of the protocrystalline material is its relative stability to light induced degradation observed for both films and corresponding solar cells. Despite the 
Pre-print E-MRS Spring 2003 June $10^{\text {th }}-13^{\text {th }}$ Strasbourg, France, Published: Wronski, C. R., J. M. Pearce, J. Deng, V. Vlahos, and R. W. Collins. "Intrinsic and light induced gap states in a-Si: H materials and solar cells_effects of microstructure." Thin Solid Films 451 (2004): 470-475. http://dx.doi.org/10.1016/j.tsf.2003.10.129

evolutionary nature of the $\mathrm{Si}: \mathrm{H}$ materials prepared with moderate $\mathrm{H}_{2}$-dilution, they exhibit relatively uniform bulk properties over certain extended regions of thickness [1]. Using phase diagrams as a guide, it is possible to identify when only protocrystalline Si:H material is present in a film or cell structure. The results on protocrystalline Si:H presented and discussed here are on thin films and solar cell structures in which the protocrystalline phase is maintained throughout the thickness of the films and the intrinsic layers of the p-i-n solar cells. The effects of the phase transitions into the mixed phase in solar cell structures have also been studied and quantified and shown to have very large effects on the cell characteristics, such as claimed to result from the bulk of the so-called "edge" materials [5].

\subsection{Gap States in Thin Film Materials}

The gap states in a-Si:H that have been the focus of attention are those associated with the dangling bond defects because the densities of $\mathrm{D}^{\mathrm{O}}$ can be measured directly with electron spin resonance. The effects of their low values $\left(<10^{16} \mathrm{~cm}^{-3}\right)$ on carrier transport and recombination and their contributions to SWE could be characterized directly. Because of the success in interpreting a plethora of results, particularly on the light induced changes solely in terms of $\mathrm{D}^{\mathrm{O}}$ defect densities, it was considered as the dominant recombination center with comparatively little attention being given to the possible role of other defects that are much more difficult to characterize. When photoconductive subgap absorption, such as the constant photocurrent method (CPM), became extensively used to characterize the densities of gap states it has been generally interpreted solely in terms of $\mathrm{D}^{\mathrm{O}}$. However there is extensive evidence that non- $\mathrm{D}^{0}$ defect states play a role in the intrinsic properties of a-Si:H as well as their light induced changes $[6,7,8]$. This has been generally overlooked in the commonly used methodology for characterizing the defect states in a-Si:H films where only the magnitudes of photoconductivity and subgap absorption, $\alpha(E)$, are taken to directly reflect the densities of gap states in the intrinsic as well as degraded states. This however is a gross oversimplification that does not take into account possible contributions of defects other than the classic dangling bonds. The contributions of the different defect states to photoconductivity are reflected in the dependence of $\mu \tau$ products on $G$, and the shape of the $\alpha(E)$ spectra.

A protocrystalline $(\mathrm{R}=10)$ film (A) and two undiluted films, one deposited at $1.5 \AA / \mathrm{s}(\mathrm{B})$, and the other at $20 \AA / s(C)$ have been investigated. Fig. 2(a) shows the $\mu$ t products as a function of $G$ for the three films in the intrinsic (annealed) state. The $\mu \tau$ products in Fig. 2(a) reflect the electron recombination through the gap states where their dependence on $G$ reflects the change brought about by the additional states that act as recombination centers as the quasi-Fermi levels move towards the band edges [9]. In the case of recombination determined solely by a single type of state located around midgap, $\mu$ s should be independent of G. However, the characteristics here point to the presence of additional defect states removed from midgap which decrease $\mu \tau$ with G. Such characteristics, rather than the one reported by Stutzmann et al. [10], are commonly found in a-Si:H films. The striking differences between these films with different microstructure are not as much the $\mu \tau$ values at $\mathrm{G}=10^{19}-10^{20} \mathrm{~cm}^{-3} \mathrm{~s}^{-1}$, corresponding to 1 sun illumination, but rather in their dependence on $\mathrm{G}$. This clearly shows that not only does the recombination occur through different defect states but also that the relative densities of these states depend on the microstructure. Higher densities of these gap states result in lower $\mu \tau$ products. However, because they also depend on the carrier capture cross-sections of the respective states, which can 
Pre-print E-MRS Spring 2003 June $10^{\text {th }}-13^{\text {th }}$ Strasbourg, France, Published: Wronski, C. R., J. M. Pearce, J. Deng, V. Vlahos, and R. W. Collins. "Intrinsic and light induced gap states in a-Si: H materials and solar cells_effects of microstructure." Thin Solid Films 451 (2004): 470-475. http://dx.doi.org/10.1016/j.tsf.2003.10.129

be very different, as well as their respective locations in the gap, relating $\mu \tau$ to their densities is extremely difficult [9].

The presence of these multiple defects and the differences in their gap state distributions is also reflected in the corresponding subgap absorption spectra, obtained with dual beam photoconductivity (DBP), shown in Fig. 2(b). Because these spectra are obtained using a normalization procedure between DBP and transmission-and-reflection measurements developed by Jiao et al. [11], it is possible to obtain reliable values for the magnitude of $\alpha(E)$ for the different films. Shown in Fig. 2(b) are the subgap absorption spectra in the annealed state (AS) as well as after 1 sun illumination at $25^{\circ} \mathrm{C}$ which are discussed later. The $\alpha(\mathrm{E})$ spectra in Fig. 2(b) for the annealed state are quite different not only in their magnitude, but also the shapes, which is not so evident between $B$ and $C$ but striking for the protocrystalline film A. Such differences in the shape of $\alpha(E)$ are a clear indication that multiple defect states are present as indicated by the results in Fig 2(a). Consequently, even though the magnitude of $\alpha(E)$ decreases with improved microstructure, the values at an arbitrary value of $\mathrm{E}$, such as the $1.2 \mathrm{eV}$ commonly used, does not directly reflect the nature or densities of the gap states. It should be pointed out here that the subgap absorption measured with photoconductivity, both CPM and DBP, is determined by the densities of electrons that occupy the gap states and are emitted by hv into the conduction band rather than the actual density of these states. The values of $\mathrm{G}$ in these subgap measurements are $10^{15} \mathrm{~cm}^{-3} \mathrm{~s}^{-1}$, which is similar to those in CPM, so only the $\mu \tau$ products at these values can be directly associated with $\alpha(\mathrm{E})$, and not those for 1 sun illumination. Attempts have been made to obtain information about the nature and densities of the gap states from the self-consistent numerical modeling of $\mu \tau$ and $\alpha(E)$ for different values of $G$ [12,13]. Self-consistency could be obtained only with multiple defect states but there are still large uncertainties about their nature and densities because of the large number of adjustable parameters that are involved in such fitting.

The effect of microstructure of a-Si:H on its gap states becomes even more pronounced with the differences in their evolution under light soaking. This is seen in kinetics of the light induced changes of the $\mu$ t products and the striking differences in the $\alpha(E)$ spectra between the annealed and degraded states in Fig. 2(b). The kinetics of the changes in $\mu \tau\left(10^{19} \mathrm{~cm}^{-3} \mathrm{~s}^{-1}\right)$ for the three films under 1 sun illumination at $25^{\circ} \mathrm{C}$ are shown in Fig. 3. The significant differences between the kinetics in the films indicate not only that there are multiple gap states but also that they are being created at different rates. This is reflected by the initial faster rates in A and B, and the approach to a degraded steady state (DSS). In the case of the protocrystalline material the DSS is reached in less than 100 hours and in the high rate undiluted material $\mathrm{B}$, with significantly lower $\mu$ t products in $\sim 1000$ hours. The kinetics in the undiluted material $\mathrm{C}$ exhibit a constant rate, close to the extensively reported $t^{1 / 3}$ dependence [10], with no approach to a DSS and $\mu$ t products significantly lower than those in B, even after 500 hours of illumination. Such differences become even more pronounced during degradation at higher temperatures [14], where at $75^{\circ} \mathrm{C}$ the protocrystalline material A reaches a DSS in $\sim 10$ hours with higher values of $\mu \tau$, the undiluted $\mathrm{B}$ material exhibits kinetics similar to those of $\mathrm{B}$ at $25^{\circ} \mathrm{C}$ and have been discussed by Pearce et al. [15] and Wronski et al. [1]. The kinetics for the undiluted material C on the other hand remain virtually unchanged at $75^{\circ} \mathrm{C}$, a reflection of its inferior microstructure. It can be noted here also that because of such differences in kinetics in materials with different microstructure, it is not possible to obtain meaningful comparisons for their relative stability and that of the corresponding solar cells without obtaining a DSS under 1 sun illumination at the operating temperature. 
Pre-print E-MRS Spring 2003 June $10^{\text {th }}-13^{\text {th }}$ Strasbourg, France, Published: Wronski, C. R., J. M. Pearce, J. Deng, V. Vlahos, and R. W. Collins. "Intrinsic and light induced gap states in a-Si: H materials and solar cells_effects of microstructure." Thin Solid Films 451 (2004): 470-475. http://dx.doi.org/10.1016/j.tsf.2003.10.129

As can be inferred from the differences in the subgap absorption spectra between the annealed and degraded states seen in Fig. 2(b) that the evolution in the three materials must be distinctly different since in the degraded state they appear to be very similar. However the magnitude of these $\alpha(E)$ spectra does not reflect the differences between the corresponding $\mu \tau$ products in Fig. 3. Such lack of correlation between the kinetics of the changes in $\mu \tau$ and those in $\alpha(1.2)$ and differences in the shapes of the absorption spectra have been reported and their importance pointed out $[1,13,16]$. As was discussed for the annealed states results, in order to characterize the changes in the gap states it is necessary to consider the evolution of the entire $\alpha(E)$ spectra. The differences in the $\alpha(E)$ spectra can be quantified with the approach described by Pearce et. al [17]. The density of electron occupied defect states, $N(E)$ at $E<h v$ from $E_{c}$ under a specific $\mathrm{G}$, is obtained from the derivatives of $\alpha(\mathrm{E})$ and is given by,

$$
\mathrm{N}(\mathrm{E})=\mathrm{k}^{-1}(\mathrm{~h} v) \mathrm{d}[\alpha(\mathrm{hv})] / \mathrm{dE}-\alpha(\mathrm{h} v)
$$

where $\mathrm{k}$ is the dipole matrix element for their transition into the conduction band, which is assumed to be constant.

The evolution in $\alpha(E)$ spectra (Fig. 2(b)) clearly reflects the creation of two distinctly different gap states which are created at different rates and that these rates depend on the microstructure of the a-Si:H. The differences in the evolution of these gap states in the three films whose $\alpha(E)$ is shown in Fig. 3, can be illustrated by normalizing the $k N(E)$ spectra after degradation to those in the annealed state. It should be pointed out here that the magnitude of such ratios is relative and depends strongly on the $\mathrm{N}(\mathrm{E})$ in the annealed state. The results indicate that the energies of the two defect states are centered around 1.0 and $1.2 \mathrm{eV}$. In the case of the protocrystalline material, the spectrum is dominated by the defect states around $1.0 \mathrm{eV}$. In the undiluted film B there is a comparable contribution of both defects to the spectrum and in the case of film $\mathrm{C}$, which has been deposited at a fast rate, the spectrum is dominated by the defect states centered around $1.2 \mathrm{eV}$ from the conduction band. These results are entirely consistent with those on $\mu \tau(\mathrm{G})$ in Fig. 2. The self-consistency with $\mu \tau$ is maintained for degradation at $75^{\circ} \mathrm{C}$ where in the protocrystalline material no contribution from the $1.2 \mathrm{eV}$ states can be seen, a dominant contribution from the $1.0 \mathrm{eV}$ defect is obtained with material $\mathrm{B}$, and the spectrum for material C remains virtually unchanged. The exact nature of these defect states has yet to be determined however, as will be discussed later, they appear to be the "fast" and "slow" states reported by Yang and Chen [18].

\subsection{Defect States in Solar Cells}

Because of the lack of direct correlations between the results on thin films and cell characteristics, particularly in their light induced changes, serious questions have been raised on whether the defect states present in thin films are the same as those present in solar cell structures. Contributing factors to this has been the focus in the thin film studies on just the $\mathrm{D}^{\circ}$ defect state and the large effects of interface recombination to the cell characteristics. In any attempt to correlate the results on thin films to the defect states in the corresponding i-layers in the solar cells, it is important to first establish that the recombination in the bulk of the cell is dominating the characteristic being studied. Because the contributions of the i-layers to the fill factor (FF) are commonly found they are most often used in evaluating the defect states in the 
Pre-print E-MRS Spring 2003 June $10^{\text {th }}-13^{\text {th }}$ Strasbourg, France, Published: Wronski, C. R., J. M. Pearce, J. Deng, V. Vlahos, and R. W. Collins. "Intrinsic and light induced gap states in a-Si: H materials and solar cells_effects of microstructure." Thin Solid Films 451 (2004): 470-475. http://dx.doi.org/10.1016/j.tsf.2003.10.129

bulk of the solar cells. There have, however, been inconsistencies reported between the nature of the light induced defects inferred from the cell FF and the results reported for thin films. They clearly point to other than $\mathrm{D}^{\circ}$ defect states being created which is consistent with the types of defect states just discussed $[7,18]$.

Because as yet the nature and densities of the states discussed earlier are not known it is not possible to correlate them directly to those in the corresponding cells, but it is possible to relate them through their role as carrier recombination centers. Such correlations are obtained with p-i-n solar cell structures in which great care was taken to reduce the contributions of the p/i interfaces [19]. In these cell structures bulk dominated carrier recombination was obtained for their forward biased I-V characteristics reflected in their dependence on thickness and light induced defects. It is important to note that these I-V characteristics are consistent with recombination through a uniform distribution of defect states across the i-layer [20,21].

Direct correlations were obtained between the recombination through the gap states in thin film materials and that in corresponding i-layers of p-i-n solar cell structures with both the protocrystalline (A) and the undiluted (B) a-Si:H i-layers exhibiting the same high FF in the annealed state. The absence of any significant difference can be explained by the FF not being yet limited by the low densities of defect states in the i-layers. However, such limitations become evident when light induced defect states are introduced. The light induced changes in the FF under 1 sun illumination at $25^{\circ} \mathrm{C}$ show a striking similarity to the kinetics of the corresponding $\mu \mathrm{t}$ products of Fig. 4. The close similarity is present in both the rates of degradation as well as the approach to a DSS. There is also the striking difference in the FFs, 0.64 vs 0.56 , after 100 hours of illumination, which is also present in the magnitudes of the corresponding $\mu \mathrm{t}$ products. No such large difference is found after 100 hours of illumination in the corresponding $\mathrm{D}^{\circ}$ defect densities in the thin film materials measured with ESR, where both are $8-10 \times 10^{16} \mathrm{~cm}^{-3}$, nor in the magnitudes of the $\alpha(E)$ spectra shown in Fig. 3. However, there is the large difference between the $\mathrm{kN}(\mathrm{E})$ spectra in Fig. 4. Because the carrier lifetimes are inversely proportional to the densities of defect states, there should be a correlation between the kinetics of the inverse of $\mu \tau$ products and those of the FFs. Such correlations are found for both types of cells, on cells with different thickness i-layers, and after degradation at different temperatures [1,19]. This is illustrated in Fig. 5 with results on $4000 \AA$ p-i-n cells during 1 sun illumination at 25 and $75^{\circ} \mathrm{C}$ where in all four cases linear relationships cane be seen between $1 / \mu \tau$ and FF.

The distinct difference between the times taken to reach the 1 sun DSS with the cells having the protocrystalline and the undiluted a-Si:H i-layers can be attributed to a difference in the relative densities of the so-called "fast" and "slow" defect states [18]. From their studies on the annealing under 1 sun illumination after degradation with high light intensities they found that the relative densities of these defects were different in the cells fabricated with and without hydrogen dilution as reflected in the relative magnitudes of the "humps" during the recoveries. Such two step experiments have been carried out on the protocrystalline (A) and the undiluted (B) a-Si:H cells and thin films with the annealing carried out not only under 1 sun illumination but also in the dark [15]. The same kinetics are observed for the cells and films where in the undiluted cell, B, there is an "overshoot" in the recovery. On the other hand for the protocrystalline cell and film not only was there no evidence of such a "hump" but also the recovery to the 1 sun DSS occurs in a much shorter time. These results indicate that the density of the "slow" defect states has been drastically reduced in the protocrystalline material. The presence of the two types of states however could be identified from the results obtained on the annealing out of the two defect states in the dark [15]. From the significantly lower contributions 
Pre-print E-MRS Spring 2003 June $10^{\text {th }}-13^{\text {th }}$ Strasbourg, France, Published: Wronski, C. R., J. M. Pearce, J. Deng, V. Vlahos, and R. W. Collins. "Intrinsic and light induced gap states in a-Si: H materials and solar cells_effects of microstructure." Thin Solid Films 451 (2004): 470-475. http://dx.doi.org/10.1016/j.tsf.2003.10.129

of the defect states centered around $1.2 \mathrm{eV}$ from $\mathrm{E}_{\mathrm{C}}$ to the $\mathrm{kN}(\mathrm{E})$ spectra of the protocrystalline aSi:H seen in Fig. 4 would thus indicate they are at least part of the "slow" states.

\section{CONCLUSIONS}

From the results on protocrystalline and undiluted a-Si:H two distinctly different gap states have been identified, centered at 1.0 and $1.2 \mathrm{eV}$ from the conduction band. This was obtained only when the presence of multiple defect states in characterizing the photoconductivity and subgap absorption of the thin films was addressed. The effects of changes in microstructure of the a-Si:H on the gap states was illustrated with the differences in the characteristics of carrier recombination and subgap absorption. Direct correlations are obtained between carrier recombination in thin films and that in the bulk of corresponding cells. The contributions of microstructural changes to the difference in the light induced changes of the two gap states were also identified. The results point to the improved stability of protocrystalline a-Si:H materials and cells as being due to the reduction of non- $\mathrm{D}^{\circ}$ states such as those at $1.2 \mathrm{eV}$ from the conduction band. Even though the nature and densities of these states have not as yet been determined, ignoring their presence leads to erroneous conclusions being drawn about the stability of a-Si:H materials and also they must be taken into account in any proposed model for SWE.

\section{References:}

[1] C.R. Wronski, J.M. Pearce, R.J. Koval, X. Niu, A.S. Ferlauto, J. Koh, and R.W. Collins, Mat. Res. Soc. Proc. 715, (2002) A13.4.

[2] X. Xu, J. Yang, S. Guha, Appl. Phys. Lett. 62, (1993)1399.

[3] M.J. Powell, S.C. Deane, Phys. Rev. B 53, (1996) 10121.

[4] R.W. Collins, A.S. Ferlauto, G.M. Ferreira, Joohyun Koh, Chi Chen, R.J. Koval, J.M. Pearce, C.R. Wronski, M.M. Al-Jassim, and K.M. Jones, Mat. Res. Soc. Proc.,762, (2003) A10.1.

[5] G. Yue, D. Han, D. L. Williamson, J. Yang, K. Lord, and S. Guha, Appl. Phys. Lett. 77(20), (2000) 3185-3187.

[6] G. Ganguly, S. Yamasaki, A. Matsuda, Phil. Mag. B. 63, (1991) 281.

[7] B. von Roedern, Appl. Phys. Lett. 62, (1993) 1368.

[8] M. Gunes and C. R. Wronski, J. Appl. Phys., 81, (1997) 3526.

[9] A. Rose, “Concepts in photoconductivity and Applied Problems”, Wiley, NY (1983).

[10] M. Stutzmann, W.B. Jackson, C.C. Tsai, Phys. Rev. B 32, (1985) 23.

[11] L. Jiao, I. Chen, R.W. Collins, C.R. Wronski, N. Hata, Appl. Phys. Lett. 72, (1998) 1057.

[12] L. Jiao, H. Liu, S. Semoushikina, Y. Lee, and C.R. Wronski, Appl. Phys. Lett. 69, (1996) 3713. 
Pre-print E-MRS Spring 2003 June $10^{\text {th }}-13^{\text {th }}$ Strasbourg, France, Published: Wronski, C. R., J. M. Pearce, J. Deng, V. Vlahos, and R. W. Collins. "Intrinsic and light induced gap states in a-Si: H materials and solar cells_effects of microstructure." Thin Solid Films 451 (2004): 470-475. http://dx.doi.org/10.1016/j.tsf.2003.10.129

[13] L. Jiao, X. Niu, Z. Lu, C. R. Wronski, A. Matsuda, T. Kamei, G. Ganguly, Solar Energy Materials and Cells, 66, (2001) 231.

[14] R. Koval, X. Niu, L. Jiao, J. Pearce, G. Ganguly, J. Yang, S. Guha, R.W. Collins, C.R. Wronski, Mat. Res. Soc. Proc. 609, (2000) A15.5.

[15] J. M. Pearce, R.J. Koval, X. Niu, S.J. May, R.W. Collins, C.R. Wronski, $17^{\text {th }}$ European PV Solar Energy Conf. Proc. 3, (2002) 2842.

[16] J. Pearce, X. Niu, R.J. Koval, G. Ganguly, D. Carlson, R.W. Collins, C.R. Wronski, Mate Res. Soc. Proc. 664, (2001) A12.3.

[17] J. M. Pearce, J. Deng, V. Vlahos, R.W. Collins, C.R. Wronski, Proceedings of the $3^{\text {rd }}$ World Conference on Photovoltaic Energy Conversion, Osaka, Japan 2003 (in press).

[18] L. Yang, L. Chen, Mat. Res. Soc. Proc. 336, (1994) 669.

[19] J. M. Pearce, R. J. Koval, R.W. Collins, C. R. Wronski, M.M. Al-Jassim, and K.M. Jones, $29^{\text {th }}$ IEEE Photovoltaic Specialists Conf. Proc., (2002) 1098-1101.

[20] J. Deng, J.M. Pearce, R.J. Koval, V. Vlahos, R.W. Collins, C.R. Wronski, Appl. Phys. Lett. 82, (2003) 3023.

[21] J. Deng, J. M. Pearce, V. Vlahos, R. W. Collins, and C. R. Wronski, Mat. Res. Soc. Proc. 2003 (in press).

\section{PAPER REFERENCE: D-III.4}

\section{List of graphics captions}

Fig. 1. Schematic of the structure of Si:H films prepared as a function of R. The dashed and dotted lines identify the $\mathrm{a} \rightarrow(\mathrm{a}+\mu \mathrm{c})$, and $(\mathrm{a}+\mu \mathrm{c}) \rightarrow \mu \mathrm{c}$ transitions, respectively.

Fig. 2(a). Electron mobility-lifetime products plotted as a function of generation rate for the A $(\mathrm{R}=10), \mathrm{B}(\mathrm{R}=01.5 \AA / \mathrm{s})$, and $\mathrm{C}(\mathrm{R}=020 \AA / \mathrm{s})$ materials in the annealed state.

Fig. 2(b). Subgap absorption spectra plotted as a function of energy for the $A(R=10), B(R=0$ $1.5 \AA / s)$, and $C(R=020 \AA / s)$ materials in the annealed state and after exposure to 1 sun illumination at $25^{\circ} \mathrm{C}$.

Fig. 3. Electron mobility-lifetime products for A ( $R=10)$, $B(R=01.5 \AA / s)$, and $C(R=020 \AA / s)$ materials exposed to 1 sun illumination at $25^{\circ} \mathrm{C}$.

Fig. 4. The $\mathrm{N}_{\mathrm{DS}}(\mathrm{E}) / \mathrm{N}_{\mathrm{AS}}(\mathrm{E})$ spectra as a function of energy for a-Si:H films $\mathrm{A}, \mathrm{B}$, and $\mathrm{C}$ after exposure to 1 sun illumination at $25^{\circ} \mathrm{C}$ for $\geq 100$ hours.

Fig. 5. The relationship of $1 / \mu \tau$ for $A(R=10)$ and $B(R=01.5 \AA / s)$ films to the fill factors of the corresponding $\mathrm{p}-\mathrm{i}-\mathrm{n}$ solar cells with $4000 \AA$ i-layers. Degradation is performed under 1 sun illumination at 25 and $75^{\circ} \mathrm{C}$. 
Pre-print E-MRS Spring 2003 June $10^{\text {th }}-13^{\text {th }}$ Strasbourg, France, Published: Wronski, C. R., J. M. Pearce, J. Deng, V. Vlahos, and R. W. Collins. "Intrinsic and light induced gap states in a-Si: H materials and solar cells_effects of microstructure." Thin Solid Films 451 (2004): 470-475. http://dx.doi.org/10.1016/j.tsf.2003.10.129

PAPER REFERENCE: D-III.4

Fig. 1
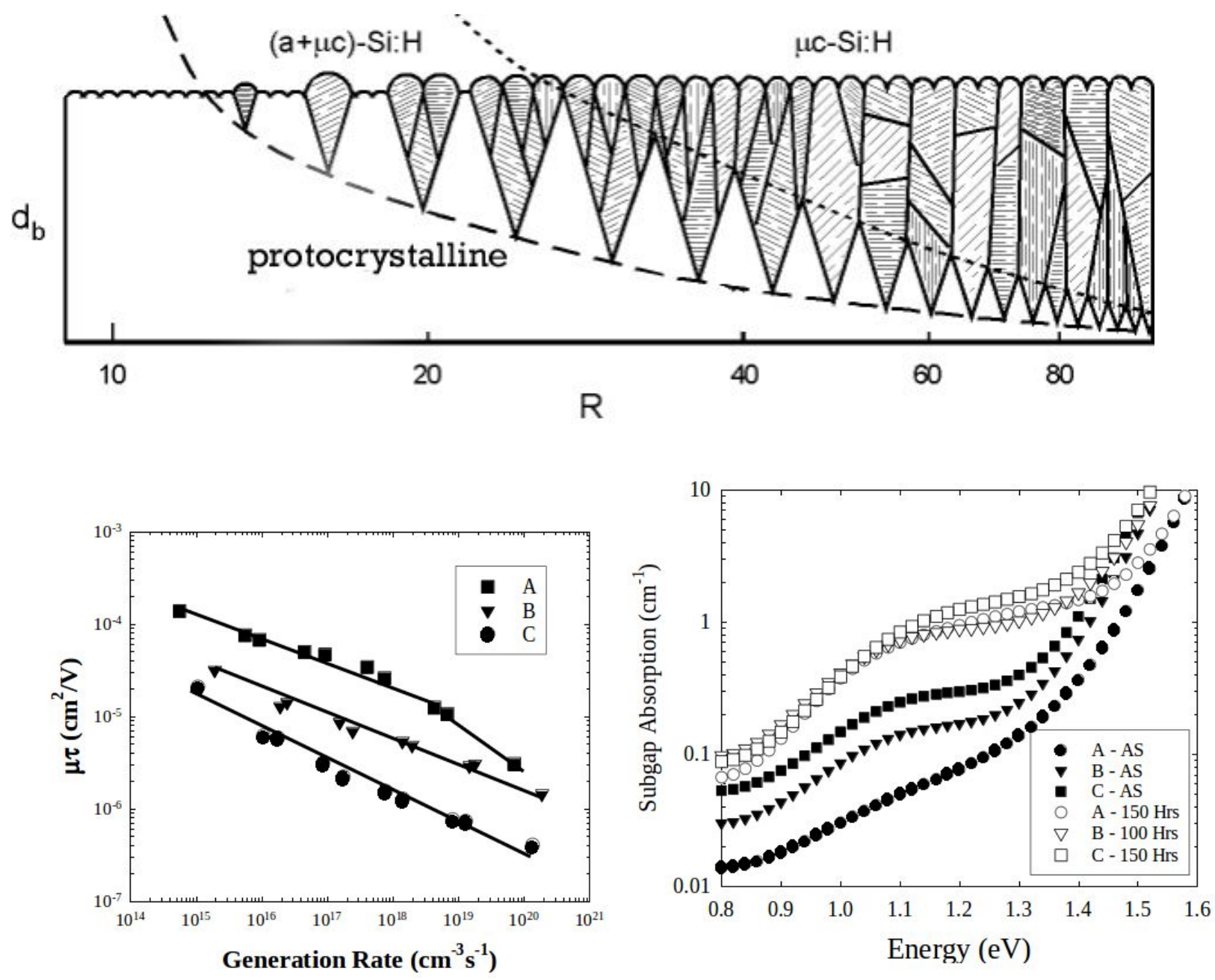
Pre-print E-MRS Spring 2003 June $10^{\text {th }}-13^{\text {th }}$ Strasbourg, France, Published: Wronski, C. R., J. M. Pearce, J. Deng, V. Vlahos, and R. W. Collins. "Intrinsic and light induced gap states in a-Si: H materials and solar cells_effects of microstructure." Thin Solid Films 451 (2004): 470-475. http://dx.doi.org/10.1016/j.tsf.2003.10.129

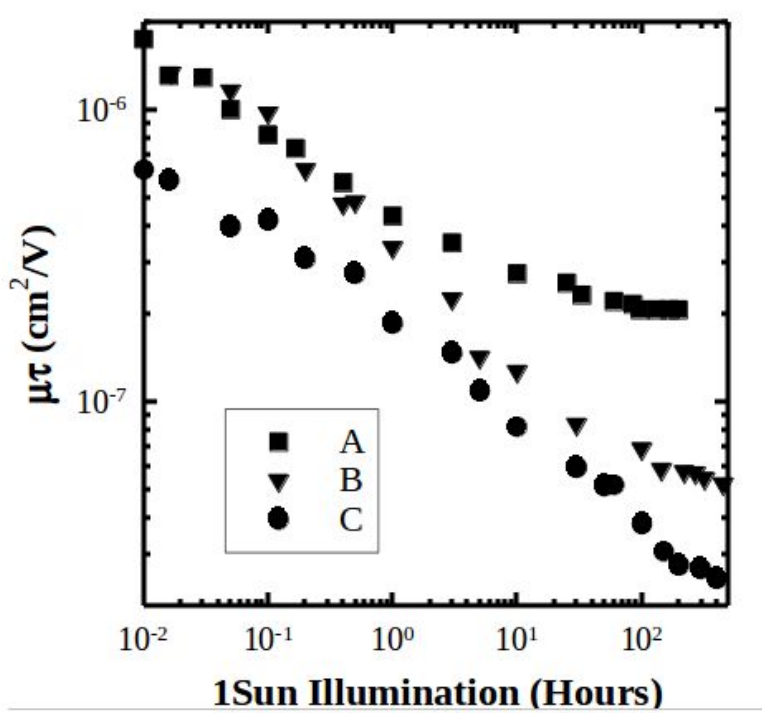

Fig. 3

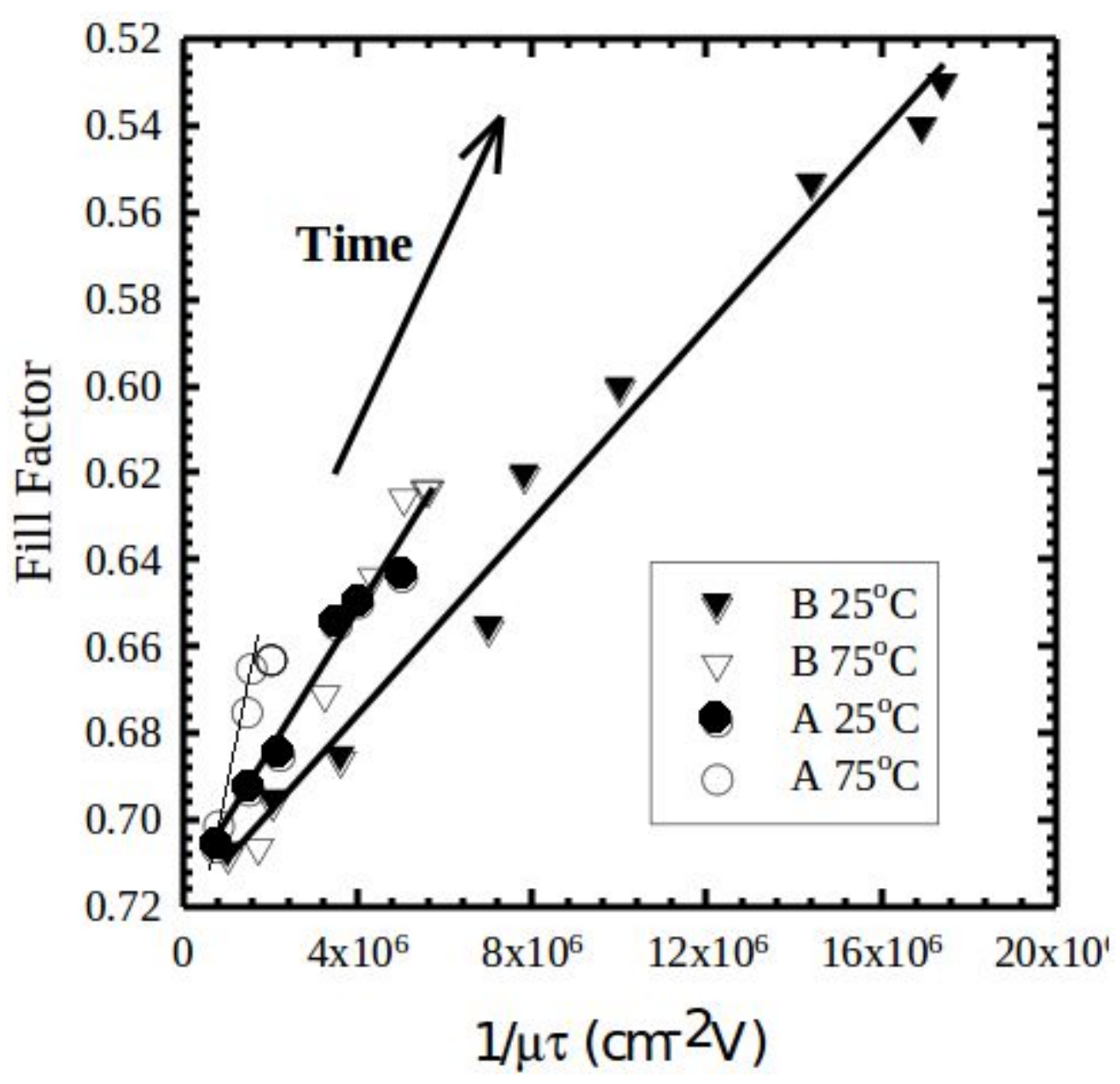

